\title{
Pengaruh Modifikasi Belitan Stator Motor Induksi Satu Phasa Starting Kapasitor Pada Mesin Bor Meja Terhadap Arus dan Daya listrik serta Putaran Motor
}

\author{
Muhammad Naim \\ Program Studi Perawatan dan perbaikan Mesin, Akademi Teknik Sorowako \\ e-mail: mnaim@ats-sorowako.ac.id
}

\begin{abstract}
Abstrak
Motor Induksi 1 phasa starting kapasitor 4 kutub yang digunakan sebagai penggerak pada mesin bor meja memiliki kontruksi yang lebih rumit karena memiliki saklar sentrifugal yang terhubung seri dengan kapasitor untuk start awal dengan arus listrik, daya listrik dan putaran rotor yang besar. Sedangkan motor induksi 3 phasa 6 kutub memiliki konstruksi yang lebih sederhana karena tidak membutuhkan saklar Sentripugal dan kapasitor untuk start awalnya dengan arus listrik, daya listrik dan putaran medan rotor yang kecil. Penelitian ini membahas tentang pengaruh modifikasi belitan stator motor induksi 1 fasa starting kapasitor 4 kutub pada mesin bor meja menjadi belitan stator motor induksi 3 fasa 6 kutub terhadap arus listrik, daya listrik dan putaran rotor motor induksi. Modifikasi dilakukan pada belitan stator motor induksi 1 phasa dengan perubahan jumlah phasa, perubahan jumlah kutub, perubahan type belitan, perubahan diameter kawat, dan perubahan jumlah lilitan peralur. Untuk itu pada penelitian ini dilakukan modifikasi pada belitan sehingga diperoleh motor induksi 3 fasa 6 kutub 24 alur dengan jumlah lilitan peralur 200 lilitan, diameter kawat $0,5 \mathrm{~mm}$, dan type belitan spiral double layer. Setelah dilakukan pengujian berbeban motor induksi pada mesin bor meja terjadi penurunan rata-rata arus listrik sebesar 3,56 Ampere atau 81,6\%, terjadi penurunan rata-rata daya listrik sebesar 191,4 Watt atau 40,06 \%, dan terjadi penurunan putaran rotor rata-rata sebesar 499,7 Rpm atau 33,75\%.
\end{abstract}

Kata Kunci : Motor induksi 1 fasa starting kapasitor, belitan stator, motor induksi 3 fasa

\begin{abstract}
A 1-phase 4-pole starting capacitor induction motor which is used as an activator of the table drilling machine has a more complicated construction because it has a centrifugal switch which is connected in series with the capacitor for its initial start and a high rotational speed of the stator field, which is $1500 \mathrm{rpm}$. While a 3-phase 6-pole induction motor has a much simpler construction because it does not require a centrifugal switch and a capacitor for its initial start with a low rotational speed of the stator field, which is $1000 \mathrm{rpm}$. This study discusses the effect of modifying the stator winding in a 1-phase 4-pole starting capacitor induction motor on the table drilling machine into a stator winding of 3-phase 6-pole induction motor on the rotation of the rotor. Modifications are carried out on the stator winding of a 1-phase induction motor by changing the number of phases, number of poles, type of winding, wire diameter and number of windings per groove. Modifications are carried out on the windings to obtain a 3phase 6-pole 24-groove induction motor with 200 windings per groove, a wire diameter of 0.5 $\mathrm{mm}$, and a winding type of spiral double layer. In our trials without a load on the induction motor the rotor rotation decreased by $33.71 \%$ from $1498 \mathrm{rpm}$ to $993 \mathrm{rpm}$, and with a load decreased by $36 \%$ from $1450 \mathrm{rpm}$ to $927 \mathrm{rpm}$.
\end{abstract}


Keywords : starting capacitor 1-phase induction motor, stator winding, 3-phase induction motor

\section{PENDAHULUAN}

\section{Latar Belakang}

Motor induksi adalah motor arus bolakbalik yang paling banyak digunakan sebagai motor penggerak di industri dengan mengkonsumsi $30-80 \%$ dari total energi industri di seluruh dunia, karena memiliki kelebihan seperti struktur dan konstruksinya yang kokoh, sederhana dan perawatannya mudah. Dalam pemakaiannya hampir sebagian mesin penggerak di industri, menggunakan motor induksi. Industri pada umumnya menggunakan motor induksi 3 fasa sebagai penggerak poros mesin jika sumber listrik yang tersedia adalah sumber listrik 3 phasa karena, motor induksi 1 fasa memiliki kelemahan karena pada umumnya memiliki daya kecil, efisiensinya relatif rendah, antara 38\% sampai 70\%. Motor induksi 1 fasa starting kapasitor yang ada pada mesin bor meja memiliki kelemahan yaitu konstruksinya yang lebih rumit dibandingkan dengan motor induksi 3 fasa dengan adanya saklar sentripugal dan kapasitor untuk start awal dan putaran medan stator yang besar $1500 \mathrm{Rpm}$. Motor induksi 1 phasa starting kapasitor pada mesin bor juga membutuhkan arus dan daya listrik yang lebih besar dibandingkan dengan motor induksi 3 phasa yang memiliki konstruksi yang sama untuk menghasilkan tenaga yang sama. Mesin bor meja yang digunakan untuk membuat lubang pada benda kerja berupa besi plat dalam pengoperasiannya membutuhkan putaran yang rendah dengan torsi yang besar agar proses pengeboran dapat dilakukan dengan baik dan aman.

\section{TINJAUAN PUSTAKA}

\section{Mesin bor meja}

Mesin bor meja adalah mesin bor yang diletakkan diatas meja. Mesin ini digunakan untuk membuat lubang pada benda kerja dengan diameter kecil (terbatas sampai dengan diameter $16 \mathrm{~mm}$ ). Prinsip kerja mesin bor meja adalah putaran motor listrik diteruskan ke poros mesin sehingga poros berputar. Selanjutnya poros berputar yang sekaligus sebagai pemegang mata bor dapat digerakkan naik turun dengan bantuan roda gigi lurus dan gigi rack yang dapat mengatur tekanan pemakanan saat pengeboran.

\section{Motor Induksi}

Motor induksi merupakan motor arus bolak-balik (ac) yang paling Iuas 
digunakan. Penggunaan motor induksi di industri adalah sebagai penggerak, seperti untuk mesin blower, kompresor, dan pompa. Sedangkan untuk peralatan workshop seperti mesin bor, gerinda, crane, dan sebagainya. Penamaan motor induksi berasal dari kenyataan bahwa arus listrik pada rotor motor induksi bukan diperoleh dari sumber tertentu, tetapi merupakan arus listrik yang terinduksi sebagai akibat adanya perbedaan relatif antara putaran rotor dengan putaran medan putar yang dihasilkan oleh arus listrik pada stator yang disebut dengan slip.( Fitzegerald $A$. E.,2002).

\section{Motor Induksi 3 Phasa}

Motor Induksi 3 phase bekerja dengan memanfaatkan perbedaan fasa dari sumber listrik untuk menimbulkan gaya putar. Motor induksi tiga fasa memiliki dua komponen dasar yaitu stator dan rotor, bagian rotor dipisahkan dengan bagian stator oleh celah udara yang sempit (air gap) dengan jarak antara 0,4 mm sampai 4 $\mathrm{mm}$. Tipe dari motor induksi tiga fasa berdasarkan lilitan pada rotor dibagi menjadi dua macam yaitu rotor belitan (wound rotor) adalah tipe motor induksi yang memiliki rotor terbuat dari lilitan yang sama dengan lilitan statornya dan rotor sangkar tupai (Squirrel-cage rotor) yaitu tipe motor induksi dimana konstruksi rotor tersusun oleh beberapa batangan logam yang dimasukkan melewati slot-slot yang ada pada rotor motor induksi, kemudian setiap bagian disatukan oleh cincin sehingga membuat batangan logam terhubung singkat dengan batangan logam yang lain. Perputaran motor pada mesin arus bolak-balik ditimbulkan oleh adanya medan putar (fluks yang berputar) yang dihasilkan dalam kumparan statornya. Medan putar ini terjadi apabila kumparan stator dihubungkan dalam fasa banyak, umurnnya tiga fasa. Hubungan dapat berupa bintang atau delta. ( Prof.TS.Mhd Soelaiman, 1995 ).

\section{Motor Induksi 1 Phasa Starting Kapasitor}

Motor induksi 1 fasa adalah motor sederhana yang beroperasi pada sumber listrik AC 1 fasa dan menghasilkan torsi akibat induksi listrik yang disebabkan oleh medan magnet bolak-balik AC. Motor induksi satu fasa adalah satu jenis dari motor-motor listrik yang bekerja berdasarkan induksi elektromagnetik. Motor Induksi 1 phasa starting kapasitor menggunakan kapasitor untuk proses star awal motor, dimana pada motor ini jumlah belitan bantu berliku sama dengan belitan utama. Kapasitor dihubungkan secara seri dengan belitan bantu. Gulungan bantu dilepas menggunakan sakelar sentrifugal ketika rotor mencapai $75 \%$ dari kecepatan sinkron. Motor terus 
berakselerasi hingga mencapai

kecepatannormal. Peringkat daya motor starting kapasitor berada di antara $120 \mathrm{~W}$ hingga 750W. Motor-motor ini biasanya memilih aplikasi seperti Kulkas, pendingin ruangan (AC), Karena torsi awal yang tinggi. (A.Rakesh,A.Sai Satyaveer, B.Rajendra Prasad, J. Kapil Bharadwaj, and S.Rahul, 2012)

\section{Kapasitor}

Kapasitor adalah suatu alat untuk menyimpan muatan dan energi. Konstruksi kapasitor umumnya terdiri dari dua buah konduktor yang berdekatan namun dipisahkan oleh dielektrik. Kapasitansi kapasitor adalah suatu kemampuan kapasitor untuk menyimpan muatan. Kapasitor elektrolit digunakan dimana sejumlah besar kapasitansi diperlukan. Seperti dalam nama yang tersirat, suatu kapasitor elektrolit berisi suatu asam aki (elektrolit). Elektrolit ini dapat dalam wujud suatu cairan kapasitor elektrolit basah dan kering. Suatu kapasitor elektrolit kering berisi dua plat metal utama yang dipisahkan oleh elektrolit. Kapasitor ditempatkan di dalam suatu aluminium container silindris.

\section{Saklar Sentrifugal}

Saklar sentrifugal adalah sebuah saklar listrik yang beroperasi dengan menggunakan kekuatan sentrifugal yang diperoleh dari sebuah batang poros yang berputar, yang umum digunakan dari suatu motor listrik. Saklar dirancang untuk mengaktifkan atau menonaktifkan sebagai fungsi yang menyangkut kecepatan pemutaran pada batang poros tersebut. Penggunaan dari saklar sentrifugal adalah di dalam motor starting kapasitor. di sini, saklar digunakan untuk memutuskan rangkaian belitan bantu (starting) dari motor ketika motor mendekati putaran nominalnya. Dalam hal ini saklar sentrifugal terdiri dari anak timbangan yang menjulang kepada batang poros dari motor dan memegang dekat batang dengan kekuatan lompatan (spring force). Pada posisi diam, pengungkit berkait dengan anak timbangan sehingga membuat suatu geseran rendah, lapisan non-konduktif melawan terhadap satu set kontak elektrik yang menjulang kepada badan motor, menutup kontak dan menghubungkan belitan bantu (starting) ke sumber. Ketika motor mencapai suatu kecepatan mendekati kecepatan operasi yang normalnya sekitar $75 \%$ dari kecepatan sinkron, gaya sentrifugal memaksa gaya spring dan anak timbangan mengayun ke luar, mengangkat plat lapisan menjauh dari kontak listrik. Sehingga menggerakkan kontak untuk membuka dan memutuskan belitan bantu dari sumber.

\section{METODE PENELITIAN}




\section{Waktu Penelitian}

Penelitian ini dilaksanakan selama 6 bulan, dimulai pada bulan Februari sampai dengan bulan Juli 2020. Pada bulan Februari sampai maret 2020 dimulai dengan studi literatur yaitu mulai mencari buku-buku, jurnal, dan artikel laporan penelitian yang terkait dengan penelitian ini. Pada bulan April dan Mei 2020 memulai tahapan perancangan untuk modifikasi belitan stator motor induksi 1 phasa starting kapasitor menjadi belitan stator motor induksi 3 phasa dan setelahnya melakukan pengumpulan alat
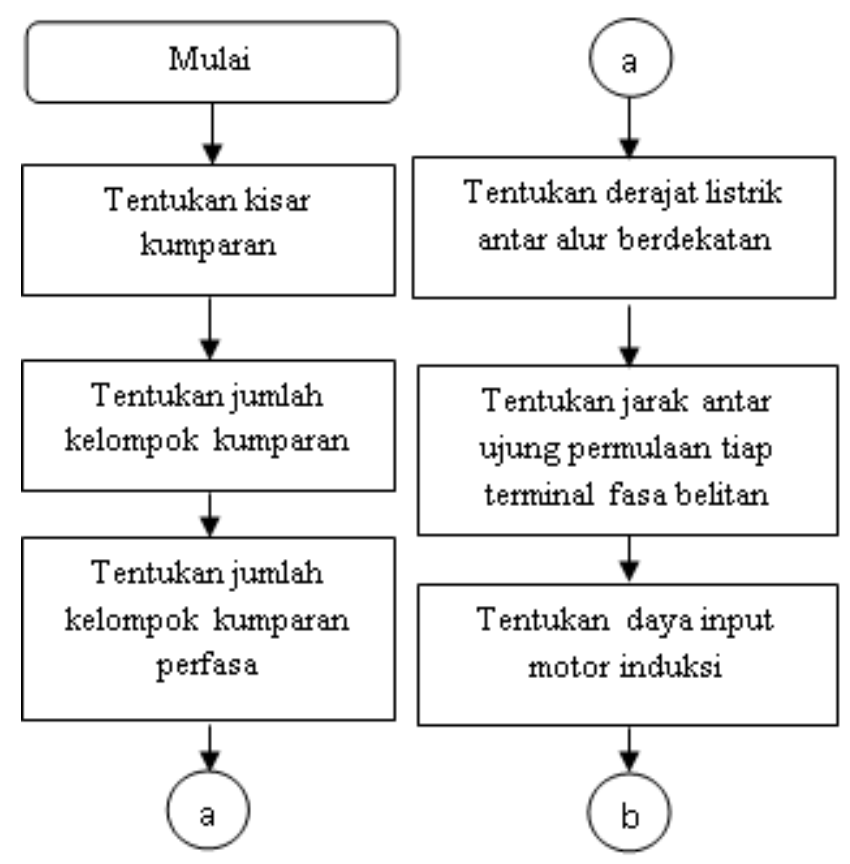

dan bahan yang dibutuhkan untuk membuat belitan stator. Terakhir, pada bulan Juni sampai Juli 2020 kami melakukan tahapan pembuatan dan menguji coba hasil modifikasi serta mencatat hasil uji coba.

\section{Tempat Pelaksanaan Penelitian}

Penelitian ini dilakukan di Bengkel Praktek Akademi Teknik Soroako Kecamatan Nuha Kabupaten Luwu Timur Provinsi Sulawesi Selatan.

\section{Diagram Proses Penelitian}

Gambar 1. Diagram Alir Perancangan modifikasi belitan stator 
Vertex Elektro, Vol.12, No.02, Tahun 2020 (Agustus) p-ISSN. 1979-9772 e-ISSN. 2714-7487

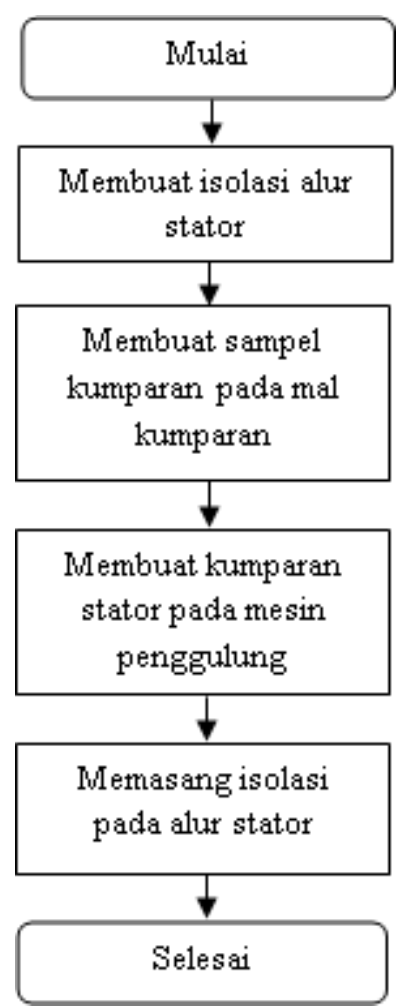

Gambar 2. Diagram Alir pembuatan belitan stator

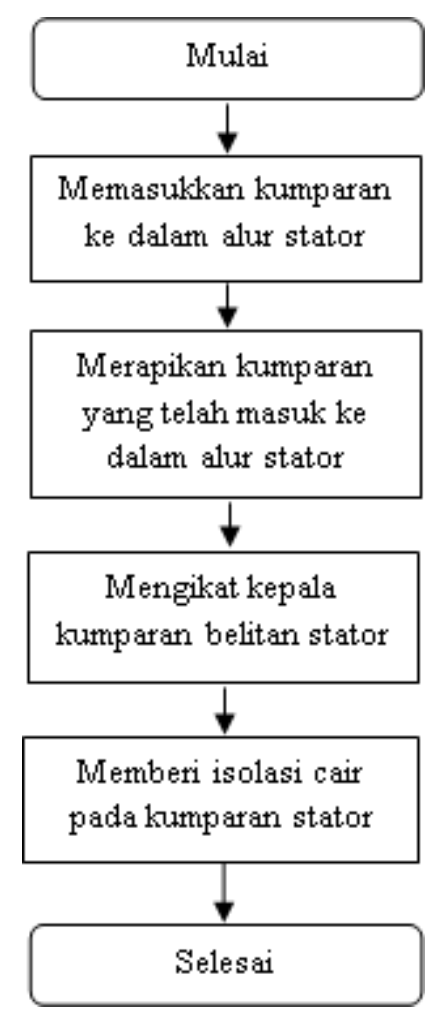

Gambar 3. Diagram Alir pemasangan belitan stator

\section{HASIL DAN PEMBAHASAN}

Dari hasil perancangan modifikasi belitan stator motor induksi dari belitan stator menjadi belitan stator motor induksi 3 phasa diperoleh gambar belitan stator motor induksi 3 phasa ditunjukkan pada gambar 4 . motor induksi 1 phasa starting kapasitor

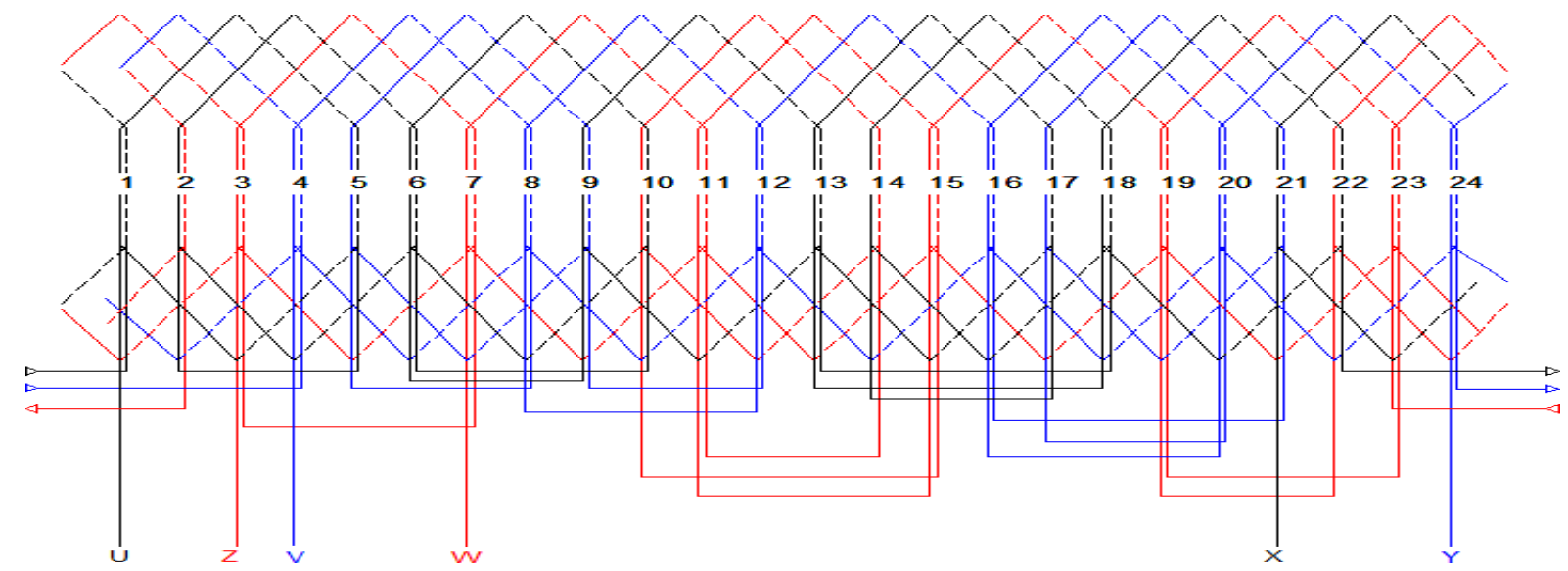

Gambar 4. Belitan stator motor induksi 3 phasa hasil modifikasi 
Setelah melakukan proses pembuatan

belitan stator motor induksi 3 phasa sesuai

gambar hasil rancangan dan melakukan

pemasangan belitan stator yang telah dibuat

ke dalam alur-alur stator motor induksi,

diperoleh hasil seperti yang ditunjukkan

pada gambar 5 .

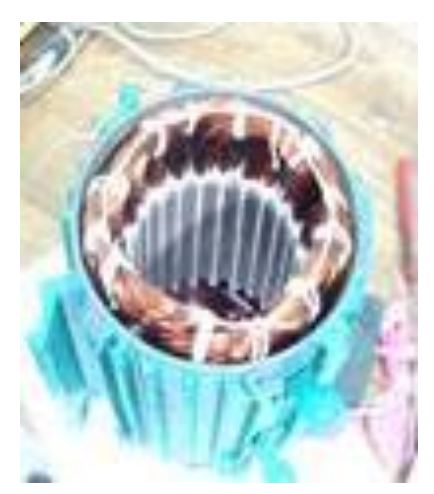

\begin{tabular}{|c|c|c|c|}
\hline $\begin{array}{c}\mathbf{N} \\
\mathbf{o}\end{array}$ & Parameter motor induski & $\begin{array}{c}\text { Motor } \\
\text { Induksi } \\
\text { Phasa }\end{array}$ & $\begin{array}{c}\text { Motor } \\
\text { Induksi 3 } \\
\text { Phasa }\end{array}$ \\
\hline 1 & Resistansi stator ( Ohm ) & 4.55 & 26.3 \\
\hline 2 & Resistansi rotor ( Ohm ) & 1.08 & 12.24 \\
\hline 3 & Reaktansi stator ( Ohm ) & 8.73 & 34.83 \\
\hline 4 & Reaktansi rotor ( Ohm ) & 8.73 & 34.83 \\
\hline 5 & $\begin{array}{c}\text { Reaktansi magnetisasi ( } \\
\text { Ohm ) }\end{array}$ & 75.55 & 341.51 \\
\hline \multicolumn{2}{|c|}{} \\
\end{tabular}

Tabel 2. Hasil pengujian berbeban pada motor induksi 1 phasa Starting Kapasitor

\begin{tabular}{|c|c|c|c|c|c|}
\hline NO & $\begin{array}{c}\text { Diameter } \\
\text { mata bor } \\
\text { (Inch })\end{array}$ & $\begin{array}{c}\text { Arus } \\
\text { listrik } \\
\text { (Ampere) }\end{array}$ & $\begin{array}{c}\text { Tegangan } \\
\text { Listrik } \\
\text { (Volt) }\end{array}$ & $\begin{array}{c}\text { Daya } \\
\text { Listrik } \\
\text { (Watt) }\end{array}$ & $\begin{array}{c}\text { Putaran } \\
\text { Rotor } \\
(\text { Rpm) }\end{array}$ \\
\hline 1 & 5 & 4.16 & 227.4 & 310 & 1491 \\
\hline 2 & 7 & 4.18 & 226.5 & 403 & 1485 \\
\hline 3 & 9 & 4.25 & 225.5 & 456 & 1481 \\
\hline 4 & 11 & 4.55 & 224.8 & 566 & 1475 \\
\hline 5 & 13 & 4.72 & 224.7 & 622 & 1470 \\
\hline
\end{tabular}

Tabel 3. Hasil pengujian berbeban pada motor induksi 3 phasa

Gambar 5. Belitan stator motor induksi 3 phasa

Setelah melakukan pengujian tanpa beban,

pengujian berbeban, dan pengujian rotor tertahan pada motor induksi 1 phasa starting kapasitor dan motor induksi 3

\begin{tabular}{|c|c|c|c|c|c|}
\hline NO & $\begin{array}{c}\text { Diameter } \\
\text { mata bor } \\
(\text { Inch })\end{array}$ & $\begin{array}{c}\text { Arus } \\
\text { listrik } \\
\text { (Ampere) }\end{array}$ & $\begin{array}{c}\text { Tegangan } \\
\text { Listrik } \\
(\text { Volt })\end{array}$ & $\begin{array}{c}\text { Daya } \\
\text { Listrik } \\
\text { (Watt) }\end{array}$ & $\begin{array}{c}\text { Putaran } \\
\text { Rotor } \\
(\mathrm{Rpm})\end{array}$ \\
\hline 1 & 5 & 0.72 & 392 & 210 & 990.1 \\
\hline 2 & 7 & 0.76 & 390 & 240 & 985.1 \\
\hline 3 & 9 & 0.79 & 389 & 260 & 980.9 \\
\hline 4 & 11 & 0.84 & 388 & 280 & 974.8 \\
\hline 5 & 13 & 0.93 & 388 & 410 & 972.7 \\
\hline
\end{tabular}

phasa hasil modifikasi pada belitan stator, diperoleh hasil pengujian yang tunjukkan pada tabel.

Tabel 1. Perbandingan parameter Motor induksi 1 fasa starting kapasitor dengan Motor induksi 3 fasa

Dari hasil pengujian berbeban motor induksi yang ditampilkan pada tabel 2 dan tabel 3, dapat dibuat grafik hubungan antara mata bor yang digunakan untuk membuat lubang pada benda kerja dengan arus listrik, daya listrik, dan putaran motor 
Dari grafik pada gambar 7, terlihat bahwa setelah dilakukan modifikasi belitan stator pada motor induksi 1 fasa starting kapasitor menjadi motor induksi 3 phasa terjadi penurunan rata-rata Daya listrik sebesar 191,4 Watt atau 40,06\%.

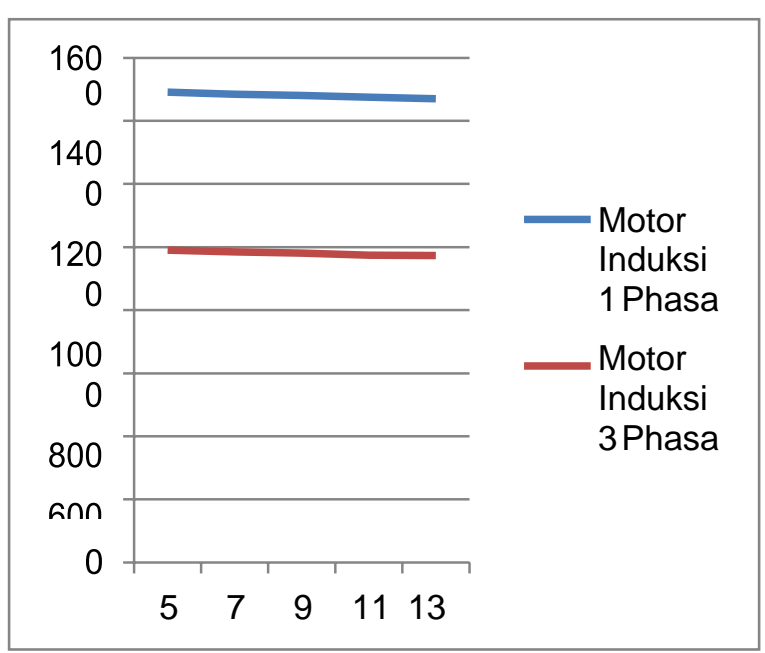

Gambar 8. Grafik hubungan antara diameter mata bor dengan putaran rotor pada motor induksi 1 dan 3 phasa

Dari grafik pada gambar 8 , terlihat bahwa setelah dilakukan modifikasi belitan stator pada motor induksi 1 fasa starting kapasitor 4 kutub menjadi motor induksi 3 phasa 6 kutub terjadi penurunan putaran rotor motor induksi sebesar 499,7 Rpm atau 33,75\%.

\section{Kesimpulan}

1. Berhasil dirancang untuk Modifikasi yang dilakukan pada belitan stator

Gambar 7. Grafik hubungan antara diameter mata bor dengan Daya listrik pada motor induksi 1 dan 3 phasa 
motor induksi 1 phasa dengan

perubahan jumlah phasa, perubahan

jumlah kutub, perubahan type belitan,

perubahan diameter kawat, dan

perubahan jumlah lilitan peralur.

2. Berhasil dibuat belitan motor induksi 3

fasa 6 kutub 24 alur dengan jumlah

lilitan peralur 200 lilitan, diameter

kawat $0,5 \mathrm{~mm}$, dan type belitan spiral

adalah double layer.

3. Hasil pengujian berbeban motor induksi pada mesiinn bor meja menunjukkan bahwa setelah dilakukannya modifikasi pada belitan stator motor induksi 1 fasa starting kapasitor 4 kutub menjadi motor induksi 3 fasa 6 kutub terjadi penurunan arus listrik rata-rata sebesar 3,56 Ampere atau 81,6 \%, terjadi penurunan daya listrik rata-rata sebesar 191,4 Watt atau 40,06\%, dan terjadi penurunan putaran rotor rata-rata sebesar 499,7 Rpm atau 33,75\%.

\section{Daftar Pustaka}

A.Rakesh,A.Sai Satyaveer, B.Rajendra Prasad, J. Kapil Bharadwaj, and S.Rahul, 2012. "Redesign of single phase induction motor (single phase to Three phase conversion)" Technological University, Hyderabad, 2012.

Deepa Vincent and Bindu R, 2013. "Three phase induction motor design in windows programming platform", International Journal of Engineering and Innovative Technology (IJEIT) Volume 3, Issue 1, July 2013.

Fernando J.T.E. Ferreira, Aníbal T. de Almeida, 2012. Induction motor down sizing as a low-cost strategy to save energy, Journal of Cleaner Production, Volume 24, March 2012, 117-131.

Fitzegerald A, 2002. E. Electric machnery ( $4^{\text {th }}$ Edition, Tata McGraw-Hill,Inc,2002).

Ihsan Staddal, Muh, \& Munir Amir ,Abdul, 2010. "Perencanaan motor induksi 3 phasa", Teknik Elektro Universitas Hasanuddin, Makassar, 2010

Ildo L. Sauer,Hédio Tatizawa,Francisco A.M. Salotti, Sonia S. Mercedes, 2014. A comparative assessment of Brazilian electric motors performance with minimum efficiency standards, Elsevier journal, 7 september 2014, 308 31

Azza M. N, and Abdel Hamid,2003. Capability of Three phase induction motor on continuous single phase operation", Journal of Electrical Engieering, VOL. 54, NO. 11-12, 2003, 281-286. 
John H. Kulhman, 1950. Design of electrical apparatus $\left(3^{\text {th }}\right.$ edition, John Wiley \& Sons Inc New York 1950).

M. Hasanuzzaman, N.A.Rahim, R. Saidur, S.N.Kazi, 2011. Energy savings and emissions reductions for rewinding and replacement of industrial motor, Energy, Volume 36, Issue 1, January 2011, 233 240.

Mehmet Akbaba, 2011. Energy conservation by using energy efficient electric motors, Elsevier Journal Applied Energy, Volume 64, Issues 1-4, 1 September 1999, 149-158. V.P. Sakthivel, S. Subramanian, On-site efficiency evaluation of three-phase induction motor based on particle swarm optimization, Elsevier Journal Applied Energy, Volume 36, Issue 3, March 2011, 1713-1720.

Prof.TS.Mhd Soelaiman, Motor Induksi dalam praktek ( Edisi ke-2, PT.Pradya Paramita Jakarta 1995 ).

Sawhney A. K. Electrical machine design. New Delhi : Dhanfat Rai \& Sons.

V. Prakash, S. Baskar, S. Sivakumar, K. Sri Krishna, 2008. A novel efficiency improvement measure in threephase induction motors, its conservation potential and economic analysis, Energy for Sustainable Development, Volume 12, Issue 2, June 2008, Pages 7887 